\title{
Neuroprotective effect of hesperidin and its combination with coenzyme Q10 on an animal model of ketamine-induced psychosis: behavioral changes, mitochondrial dysfunctions, and oxidative stress
}

\author{
Naresh Kumar, Monu Yadav, Anil Kumar* ${ }^{*}$, Monika Kadian and Sunil Kumar
}

\begin{abstract}
Background: Psychosis is a complex mental illness divided by positive symptoms, negative symptoms, and cognitive decline. Clinically available medicines are associated with some serious side effects which limit their use. Treatment with flavonoids has been associated with delayed onset and development, decreased risk, or increased improvement of various neuropsychiatric disorders including psychosis with negligible side effects. Therefore, the present study was aimed to investigate the protective effects of hesperidin (flavonoid) alone or its combination with coenzyme Q10 against ketamine-induced psychotic symptoms in mice.

Results: Ketamine (50 mg/kg, i.p.) was given for 21 days to induce psychosis in Laca mice of either sex. Locomotor activity and stereotypic behaviors, immobility duration (forced swim test), and increased transfer latency (elevated plus maze) were performed to test the effect of hesperidin $(50 \mathrm{mg} / \mathrm{kg}, 100 \mathrm{mg} / \mathrm{kg}, 200 \mathrm{mg} / \mathrm{kg}$, p.o.) and coenzyme Q10 (20 mg/kg, $40 \mathrm{mg} / \mathrm{kg}$, p.o.) and combination of hesperidin + coenzyme Q10 followed by biochemical and mitochondrial complexes assays. For 21 days, ketamine $(50 \mathrm{mg} / \mathrm{kg}$, i.p.) administration significantly produced increased locomotor activity and stereotypic behaviors (positive symptoms), increased immobility duration (negative symptoms) and cognitive deficits (increases transfer latency) weakens oxidative defense and mitochondrial function. Further, 21 days' administration of hesperidin and coenzyme Q10 significantly reversed the ketamine-induced psychotic behavioral changes and biochemical alterations and mitochondrial dysfunction in the discrete areas (prefrontal cortex and hippocampus) of mice brains. The potential effect of these drugs was comparable to olanzapine treatment. Moreover, the combination of hesperidin with coenzyme Q10 and or a combination of hesperidin + coenzyme Q10+ olanzapine treatment did not produce a significant effect compared to their per se effect in ketamine-treated animals.
\end{abstract}

Conclusions: The study revealed that hesperidin alone or in combination with coenzyme Q10 could reduce psychotic symptoms and improve mitochondrial functions and antioxidant systems in mice, suggesting neuroprotective effects against psychosis.

Keywords: Psychosis, Ketamine, Hesperidin, Coenzyme Q10, Mitochondrial dysfunctions, Antioxidant system

\footnotetext{
*Correspondence: kumaruips@yahoo.com

Faculty of Pharmaceutical Sciences, University Institute of Pharmaceutical

Sciences, UGC Centre of Advanced Studies (UGC-CAS), Panjab University,

Chandigarh 160014, India
} 


\section{Background}

Psychosis is a psychological multifactorial disorder categorized into positive symptoms (delusions, hallucinations), negative symptoms (apathy, suicidal thoughts, social detachment), and cognitive decline [1]. Ketamine, dizocilpine (MK-801), and phencyclidine block $\mathrm{N}$-methyl-D-aspartate receptors (NMDA-Rs) activating channels that cause symptoms similar to psychosis [2]. Some antipsychotics have shown an agonistic effect on NMDA-Rs. Based on these studies, it has been confirmed that reduced signaling pathways for NMDA-Rs are involved in the pathophysiology of psychosis. Mitochondrial dysfunction can cause biochemical cascade dysfunction and it has been found that the electron transport chain is an imperative factor for the pathophysiology of psychosis [3, 4].

Oxidative stress has also been associated with the worsening of neuropsychiatric disorders like psychosis. Endogenous antioxidants like glutathione (GSH), catalase and superoxide dismutase (SOD) are reduced in the psychotic brain of animals and humans. Oxidative stress is also reported to cause mitochondrial dysfunction which further leads to produce psychotic symptoms especially negative and cognitive symptoms. Ketamine is reported to produce mitochondrial dysfunction and oxidative stress that further lead to cause psychosis in mice [2]. Clinically, there are typical and atypical antipsychotics are available but there are associated several side effects such as agitation, catalepsy, sedation, tardive dyskinesia, weight gain, agranulocytosis, cardiovascular disorder, and diabetes mellitus. In addition to side effects, available antipsychotics are also associated with non-compliance, increased risk of psychotic relapse, and incomplete efficacy. Thus, there is an emerging need to investigate such a therapeutic agent by exploring new pathways that can overcome these side effects against psychotic symptoms [1].

Medical plants and their phytoconstituents possess structural similarity, biochemical specificity, chemical diversity, and therapeutic efficacy that purpose them as a therapeutic medicine for the treatment of neuropsychiatric disorders with negligible side effects. Many natural compounds have been studied against various psychiatric disorders, some of them are chosen as an alternative agent for psychosis such as niacin, D-serine, glycine, omega-3-polyunsaturated fatty acids, sarcosine, papaverine, vitamin $\mathrm{C}$, and $\mathrm{E}$. Flavonoids are ubiquitous phytoconstituents that are richly present in various foods, grains, fruits, seeds, tea, nuts, and traditional medicinal plants [5]. The key structural group in flavonoids involved in the treatment of psychosis is sites produced by hydroxyl groups for the complexing of calcium $\left(\mathrm{Ca}^{2+}\right)$ and restoring the function of NMDA-Rs, thus decreasing the psychotic symptoms. Moreover, flavonoids are rich in the antioxidant property. Some of the flavonoids like gallic acid, luteolin, quercetin, myricetin, etc. have been studied against psychosis $[6,7,9,10]$. Also, some preclinical studies have shown that flavonoids have a neuroprotective role in restoring mitochondrial function, raising GABAergic activity and acetylcholinergic neurons [11-13]. The increased GABAergic transmission demonstrated an inhibitory control of dopaminergic hyperactivity while reducing psychotic symptoms [14]. Moreover, flavonoids are reported to have antioxidant and mitochondrial function restoring properties and can produce protective effects in case of psychosis [7, 13, 14]. Moreover, extract of various plants such as Ocimum Sanctum Spinacia Oleracea Seeds, Eucalyptus Globulus Tinospora Cordifolia, Panax Quinquefolium, and Albizia Zygia has been studied previously. As the plant extracts have various constituents therefore it is very difficult to elucidate that which compound is responsible for the therapeutics activity. Hence, it is effective to study individual isolated compound for better understanding.

The animal study provides an opportunity to decipher the relationships between the nervous system and psychotic behaviors. It is necessary to test a potential compound on animals before clinical studies. Laca mice have been used in the investigation of neuropsychiatric disorders in literature.

With this background, this study was also aimed to investigate the antioxidant and mitochondrial restoring profile of hesperidin (a flavonoid) and its combination with coenzyme Q10 against ketamine-induced psychotic behaviors in mice.

\section{Methods}

\section{Drugs and chemicals}

The present research included ketamine (Neon Pharmaceutical Private Limited, India), olanzapine (Intas Pharmaceutical Limited, Ahmedabad, India), hesperidin (Sigma-Aldrich, Mohali, Chandigarh, India), and coenzyme Q10 (Hi-Media Laboratories Private Limited, India). All other chemicals used for biochemical and mitochondrial assays were of analytical reagent grade obtained from Sigma-Aldrich, Mohali, Chandigarh, India).

\section{Experimental design}

Healthy and diseased free Laca mice of either sex (3-4 months old, weighing 25-30 g) were procured from the Central Animal House (CAH), Panjab University, and used in the present study. The protocol was approved by the Institutional Animal Ethics Committee with protocol number PU/45/99/CPCSEA/IAEC/2019/289. Six animals were randomly housed in a cage and acclimatized for 
7 days before the start of experiments and free access to standard laboratory food and water and taken care of by a veterinary. They were housed in a natural ( $12 \mathrm{~h}$ each) light-dark cycle. The care of animals was taken according to Committee for the Purpose of Control and Supervision on Experiments (CPCSE) on Animals guidelines.

\section{Drugs protocol}

Ketamine was dissolved in saline and administered intraperitoneally (i.p.). Hesperidin and coenzyme Q10 (CoQ10) were suspended in $0.5 \% \mathrm{w} / \mathrm{v}$ sodium carboxymethylcellulose (CMC) (Hi-Media Laboratories Private Limited, India) solution and administered per oral (p.o.). Olanzapine was suspended in Tween $80(0.01 \%$ as a suspending agent in normal saline) (Hi-Media Laboratories Private Limited, India) and administered intraperitoneal (i.p.). In present study, doses of hesperidin $(50 \mathrm{mg} / \mathrm{kg}$, $100 \mathrm{mg} / \mathrm{kg}, 200 \mathrm{mg} / \mathrm{kg}$, p.o.), ketamine (50 mg/kg, i.p.), olanzapine (5 mg/kg, i.p.) and coenzyme Q10 (20 mg/ $\mathrm{kg}, 40 \mathrm{mg} / \mathrm{kg}$, p.o.) were used. Total sixty animals were used for the present study and randomly divided into ten groups and each group consisted of six animals for behavioral study of which five animals were used for biochemical studies and mitochondrial complexes assay (Table 1).

\section{Study protocol}

In this study, ketamine $(50 \mathrm{mg} / \mathrm{kg}$, i.p.) has been administered for 21 days to cause locomotor dysfunction (positive symptoms), stereotypic behaviors (positive symptoms), immobility (negative symptoms), and cognitive impairment in animals. Ketamine was administered after 15 min of drug treatment and locomotor activity, stereotypic behaviors, and transfer latency on the days 7,14 , and 21 and immobility duration was measured on day 21 of the experiment by two blind investigators and

Table 1 Grouping of the experimental animals

\begin{tabular}{|c|c|}
\hline Groups & Treatment \\
\hline 1 & Control \\
\hline 2 & Ketamine (50 mg/kg; i.p.) \\
\hline 3 & Ketamine + Hesperidin (50 mg/kg; p.o.) \\
\hline 4 & Ketamine + Hesperidin (100 mg/kg; p.o.) \\
\hline 5 & Ketamine + Hesperidin (200 mg/kg; p.o.) \\
\hline 6 & Ketamine + CoQ10 (20 mg/kg; p.o.) \\
\hline 7 & Ketamine + CoQ10 (40 mg/kg; p.o.) \\
\hline 8 & Ketamine + Olanzapine (5 mg/kg; p.o.) \\
\hline 9 & $\begin{array}{l}\text { Ketamine + Hesperidin (100 mg/kg; p.o.) + CoQ10 ( } 40 \text { mg/ } \\
\text { kg; p.o.) }\end{array}$ \\
\hline 10 & $\begin{array}{l}\text { Ketamine + Hesperidin (100 mg/kg; p.o.) + Olanzapine ( } 5 \text { mg/ } \\
\text { kg; p.o.) + CoQ10 ( } 40 \text { mg/kg; p.o.) }\end{array}$ \\
\hline
\end{tabular}

mentor of the study was aware. After behavioral studies, mice were sacrificed and their brains were isolated for biochemical estimations and mitochondrial complexes assays.

\section{Actophotometer}

On the days 7, 14, and 21 of the experimental protocol locomotor activity was counted using an actophotometer (IMCORP, Ambala, India), having a square-shaped sound-free chamber with six pairs of light receivers and transmitters. The animal was put on the mesh floor of the actophotometer for $5 \mathrm{~min}$ for familiarization. The locomotor score was calculated for the next 5 min after 15 min of administration of ketamine [15].

\section{Stereotypic behaviors}

Each mouse was individually placed into a plexiglass compartment $(30 \times 24 \times 22 \mathrm{~cm})$ and after $30 \mathrm{~min}$ of administration of ketamine, the stereotypic behaviors (falling, turnarounds, weaving, and head bobbing) were counted for $10 \mathrm{~min}$ on the days 7, 14 and 21 of the experimental protocol [16].

\section{Elevated plus maze (EPM)}

The maze is elevated at $25 \mathrm{~cm}$ from the floor and has two covered arms and two open arms of $16 \times 5 \mathrm{~cm} \times 12 \mathrm{~cm}$ and both the arms were $5 \mathrm{~cm} \times 5 \mathrm{~cm}$ extended from a central platform. On the day 7 , acquisition memory was recorded. A mouse was put at one end facing toward the open arm. The time taken by the animals to move from the open arm into closed arms was considered as initial transfer latency (ITL). Individual mice were permitted for $30 \mathrm{~s}$ to explore the maze after measured ITL and returned to their home cage. On the days 14 and 21 of the ITL, retention memory was measured by placing each mouse similarly on an open arm and retention latency was recorded again considered as first retention transfer latency (1st RTL) and second retention transfer latency (2nd RTL), respectively [17].

\section{Forced swim test (FST)}

In the FST, mouse was forced to swim into a glass chamber $\left(25 \times 15 \times 25 \mathrm{~cm}^{3}\right)$ containing water $(15 \mathrm{~cm})$ at $23 \pm 2{ }^{\circ} \mathrm{C}$. In this test, when mice get immobile with limited floating, relative to negative symptoms found in patients with psychosis is known as behavioral despair. During the experiment, the animal was placed for $2 \mathrm{~min}$ in the glass chamber for habituation and thereafter immobility duration was measured within the next $4 \mathrm{~min}$ on day 21 after $24 \mathrm{~h}$ of training $[18,19]$. 
Experimental procedure for mitochondrial enzyme complex assays and biochemical estimations Methods of euthanasia in mice

Mice were sacrificed using decapitation by the cervical dislocation method and their brains were rapidly removed to separate the cerebral prefrontal cortex region and hippocampus of the brain.

\section{Isolation and preparation of brain homogenate} for mitochondrial enzyme complex assays and biochemical estimations

Differential centrifugation method was used to isolate mitochondria with slight modifications [20]. Briefly, the tissue of interest (prefrontal cortex region and hippocampus) was dissected out and weighed. $10 \%(\mathrm{w} / \mathrm{v})$ tissue homogenates were prepared in ice-cold isolation buffer with $1.0 \mathrm{mM}$ ethylene glycol-bis( $\beta$-aminoethyl ether)$N, N, N^{\prime}, N^{\prime}$-tetraacetic acid (EGTA), [215 mM mannitol, $75 \mathrm{mM}$ sucrose, $0.1 \%$ fat-free bovine serum albumin (BSA), 20 mM 4-(2-hydroxyethyl)-1-piperazineethanesulfonic acid) (HEPES), 1.0 mM EGTA and $\mathrm{pH}$ is adjusted to 7.2 with potassium hydroxide $(\mathrm{KOH})]$. All procedures were performed on ice throughout the protocol. Above homogenates were then used for centrifugation at $1000 \times g$ for $8 \mathrm{~min}$ at $4{ }^{\circ} \mathrm{C}$. The supernatants, so-called post-nuclear supernatant (PNS) were taken in Eppendorf and centrifuged at $4{ }^{\circ} \mathrm{C}$ for $10 \mathrm{~min}$ at $10,000 \times g$. The obtained supernatant was collected in Eppendorf and used for biochemical estimation and Pellets, (containing mitochondria of interest) were re-suspended in isolation buffer and mitochondrial solutions were centrifuged at $4{ }^{\circ} \mathrm{C}$ for $10 \mathrm{~min}$ at $10,000 \times g$. Then the pellets were collected and re-suspended into isolation buffer $(1.0 \mathrm{ml})$ without EGTA and again centrifuged at $12,300 \times g$ for $10 \mathrm{~min}$ at $4{ }^{\circ} \mathrm{C}$ and this step was performed twice. The final re-suspended the mitochondrial pellets in isolation buffer $(200 \mu \mathrm{l})$ without EGTA and was used for the estimation of activity of mitochondrial enzyme complexes [20].

\section{Estimation of protein}

The protein content was measured as per Bradford, 1976. The standard curve of bovine serum albumin was used to determine protein concentration expressed in $\mu \mathrm{g} / \mathrm{ml}$. Thus, the values obtained were used in the calculations of other biochemical results [21].

\section{Estimation of reduced glutathione (GSH) level}

Reduced glutathione in both prefrontal cortex and hippocampus regions was done as per Ellman [22]. First, $1.0 \mathrm{ml}$ of homogenate with $1.0 \mathrm{ml}$ of $4 \%$ sulfosalicylic acid was precipitated by holding the mixture at $4{ }^{\circ} \mathrm{C}$ for $1 \mathrm{~h}$, and the samples were immediately centrifuged at $1200 \times g$ at $4{ }^{\circ} \mathrm{C}$ for $15 \mathrm{~min}$. The assay mixture includes the $0.1 \mathrm{ml}$

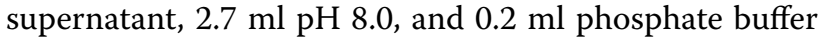
of $0.01 \mathrm{M}$ dithiobisnitrobenzoic acid (DTNB). The yellow color produced was read at $412 \mathrm{~nm}$ using an Ultraviolet (UV)-spectrophotometer (UV 1900 Shimadzu). The results are calculated using the extinction coefficient of the molar chromophore $\left(1.36=104(\mathrm{~mol} / \mathrm{l})^{-1} \mathrm{~cm}^{-1}\right)$.

\section{Estimation of catalase activity}

The catalase activity in both prefrontal cortex and hippocampus regions was measured by the method of Luck, 1965. In short, the assay mixture consisted of $1.95 \mathrm{ml}$ of phosphate buffer (0.05 M, pH 7.0), $1.0 \mathrm{ml}$ of hydrogen peroxide $(0.019 \mathrm{M})$, and $0.05 \mathrm{ml}$ of brain tissue homogenate in a final volume of $3.0 \mathrm{ml}$. The absorbance changes were recorded at $240 \mathrm{~nm}$. The activity of catalase was measured in $\mathrm{k}$ minute-1 terms [23].

\section{Estimation of superoxide dismutase (SOD) activity}

SOD activity in both the prefrontal cortex and hippocampus regions was assayed by the method of Kono, 1978. The method consisted of ethylenediaminetetraacetic acid (EDTA) $(0.1 \mathrm{mM})$, sodium carbonate $(50 \mathrm{mM})$, and nitroblue tetrazolium (96 mM). $2 \mathrm{ml}$ of the above mixture was taken in a cuvette and $0.05 \mathrm{ml}$ of brain tissue homogenate and $0.05 \mathrm{ml}$ of hydroxylamine hydrochloride was added to it [adjusted to $\mathrm{pH} 6.0$ with sodium hydroxide $(\mathrm{NaOH})$ ]. The auto-oxidation of hydroxylamine was observed by measuring the change in optical density at $560 \mathrm{~nm}$ for $2 \mathrm{~min}$ at 30/60 s intervals [24].

\section{Complex I (NADH dehydrogenase) activity}

Nicotinamide adenine dinucleotide (NADH) dehydrogenase activity in both prefrontal cortex and hippocampus regions was assessed by spectrophotometry as per the King and Howard 1967, which involves catalytic oxidation of $\mathrm{NADH}$ to nicotinamide adenine dinucleotide ion $(\mathrm{NAD}+)$ with subsequent cytochrome-C reduction [25]. The reaction was triggered by the addition of the required amount of solubilized mitochondrial sample and the absorbance change was recorded at $550 \mathrm{~nm}$ over 2 min by enzyme-linked immunosorbent assay (ELISA) microplate absorbance reader (Biorad-I USA).

\section{Complex II (succinate dehydrogenase) activity}

Succinate dehydrogenase (SDH) activity in both prefrontal cortex and hippocampus regions was measured by spectrophotometry using the King method [26], which involves the oxidation of succinate by an artificial electron acceptor (potassium ferricyanide). The reaction mixture consisted of $0.2 \mathrm{M}$ phosphate buffer $(\mathrm{pH} 7.8)$, 1\% BSA, $0.6 \mathrm{M}$ succinic acid, and $0.03 \mathrm{M}$ potassium 
ferricyanide. The addition of the mitochondrial brain sample was used to initiate the reaction and absorbance change recorded at $420 \mathrm{~nm}$ for $2 \mathrm{~min}$ by ELISA microplate absorbance reader (Biorad-I USA).

\section{Complex III (mitochondrial redox) activity}

The MTT [3-(4,5-dimethylthiazol-2-yl)-2,5-diphenyl$\mathrm{H}$-tetrazolium bromide] assay in both prefrontal cortex and hippocampus regions was dependent on reducing the activity of MTT in functionally intact mitochondria through hydrogenase. The MTT reduction rate was used to assess the mitochondrial respiratory chain activity in isolated mitochondria [27]. In short, $100 \mu \mathrm{l}$ mitochondrial samples were incubated for $3 \mathrm{~h}$ with $10 \mu \mathrm{l}$ MTT at $37^{\circ} \mathrm{C}$. Dimethyl sulfoxide was used to solubilize the blue formazan crystals and measured at $580 \mathrm{~nm}$ by ELISA microplate absorbance reader (Biorad-I USA).

\section{Complex IV (cytochrome oxidase) activity}

Cytochrome oxidase activity in both prefrontal cortex and hippocampus regions was assayed by the Sottocasa method 1967. The reaction mixture consisted of reduced cytochrome-C $(0.3 \mathrm{mM})$ in a $75 \mathrm{mM}$ phosphate buffer and the reaction began with the addition of solubilized mitochondrial samples [28]. The change in absorbance was recorded at $550 \mathrm{~nm}$ for $2 \mathrm{~min}$ by the ELISA microplate absorbance reader (Biorad-I USA).

\section{Statistical analysis}

All values were expressed as Mean \pm standard error of the mean (SEM). Results were analyzed by Bonferroni test using two-way analysis of variance (ANOVA) for locomotor activity, stereotypic behaviors, transfer latency, and one-way ANOVA followed by Turkey's test for immobility duration, mitochondrial enzyme complex assay, and biochemical estimations using Graphpad prism software 5 . The value $p<0.05$ was considered as statistical significance.

\section{Results}

Behavioral assessments

Effect of hesperidin and coenzyme Q10 on locomotor activity using actophotometer

Ketamine $(50 \mathrm{mg} / \mathrm{kg}$, i.p.) treatment significantly $(p<0.05)$ caused hyperlocomotion on days 7 and 14 and hypolocomotion (decreased locomotor activity) on day 21 compared to the naïve group. Treatment with hesperidin $(50 \mathrm{mg} / \mathrm{kg}, 100 \mathrm{mg} / \mathrm{kg}, 200 \mathrm{mg} / \mathrm{kg})$ and coenzyme Q10 (20 mg/kg, $40 \mathrm{mg} / \mathrm{kg})$ significantly $(p<0.05)$ reduced ketamine-induced locomotor dysfunction on days 7,14 and 21 . The effect of these drugs [hesperidin $(200 \mathrm{mg} / \mathrm{kg})$ and coenzyme Q10 $(20 \mathrm{mg} / \mathrm{kg}, 40 \mathrm{mg} /$ $\mathrm{kg})$ ] were comparable to that of olanzapine $(5 \mathrm{mg} / \mathrm{kg})$ treatment in ketamine-treated animals. Further, a combination of hesperidin $(100 \mathrm{mg} / \mathrm{kg})$ with coenzyme Q10 $(40 \mathrm{mg} / \mathrm{kg})$ did not produce any significant protective effect on hyper locomotor activity on days 7 and 14 and hypolocomotor activity on day 21 as compared to their effect per se in ketamine-treated animals. However, the trend of reduced hyperlocomotion on days 7 and 14 and increased hypolocomotion on day 21 was observed in these combination groups as compared to their treatment alone. Whereas, the combination of hesperidin $(100 \mathrm{mg} / \mathrm{kg})+$ coenzyme Q10 $(40 \mathrm{mg} / \mathrm{kg})$ + olanzapine $(5 \mathrm{mg} / \mathrm{kg})$ significantly $(p<0.05)$ reversed ketamineinduced hyperlocomotion on days 7 and 14 (Fig. 1).

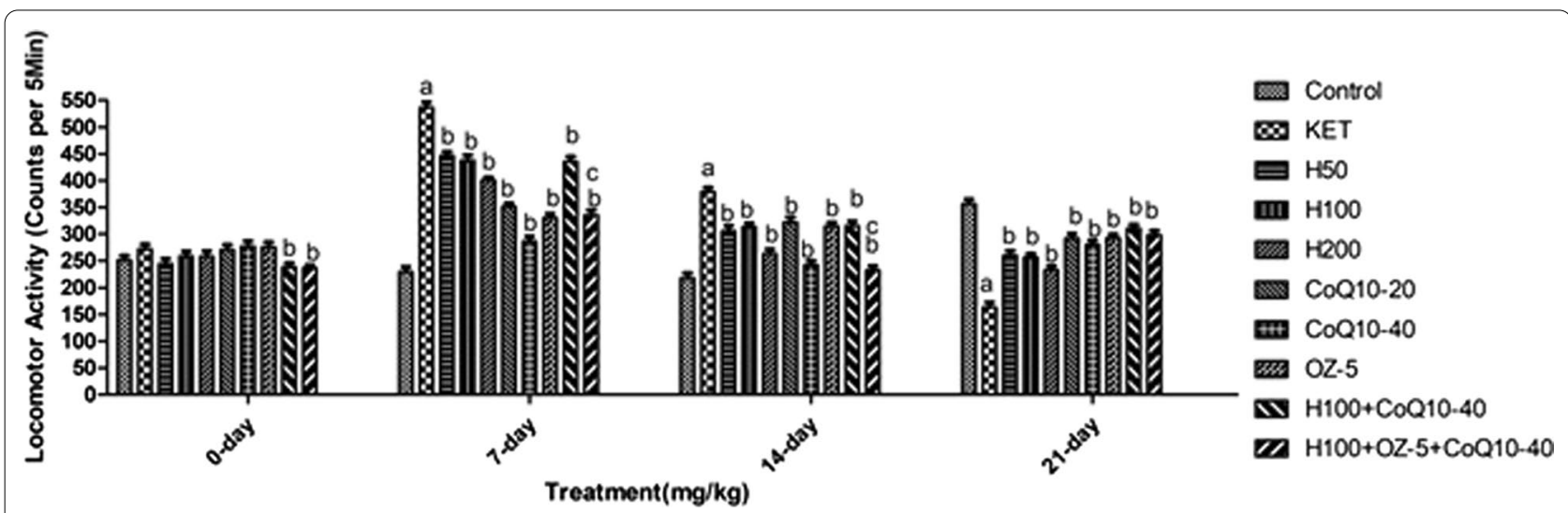

Fig. 1 Effect of Hesperidin, Coenzyme Q10, Olanzapine and their combinations on ketamine-induced locomotor dysfunction. Data were analyzed by two-way ANOVA followed by the Bonferroni test. All values were expressed as Mean \pm SEM. ${ }^{a} p<0.05$ as compared to naive, ${ }^{b} p<0.05$ as compared to ketamine, ${ }^{c} p<0.05$ as compared to Hesperidin (100 mg/kg). KET, Ketamine; H, Hesperidin; CoQ10, Coenzyme Q10; OZ, Olanzapine 


\section{Effect of hesperidin and coenzyme Q10 on stereotypic behavior}

Ketamine $(50 \mathrm{mg} / \mathrm{kg})$ treatment significantly $(p<0.05)$ produced the stereotypic behaviors on days 7,14 , and 21 as compared to the naïve group of animals. Treatment with hesperidin $(50 \mathrm{mg} / \mathrm{kg}, 100 \mathrm{mg} / \mathrm{kg}, 200 \mathrm{mg} / \mathrm{kg}$ ) and coenzyme Q10 $(20 \mathrm{mg} / \mathrm{kg}, 40 \mathrm{mg} / \mathrm{kg})$ significantly $(p<0.05)$ reversed ketamine-induced stereotypic behavior on days 7, 14 and 21 . The effect of hesperidin $(100 \mathrm{mg} /$ $\mathrm{kg}$ and $200 \mathrm{mg} / \mathrm{kg}$ ) was comparable to that of olanzapine $(5 \mathrm{mg} / \mathrm{kg})$ treatment in ketamine-treated animals. Further, a combination of hesperidin $(100 \mathrm{mg} / \mathrm{kg})$ with coenzyme Q10 $(40 \mathrm{mg} / \mathrm{kg})$ and or a combination of hesperidin $(100 \mathrm{mg} / \mathrm{kg})+$ coenzyme Q10 (40 mg/kg) + olanzapine $(5 \mathrm{mg} / \mathrm{kg})$ did not produce any significant protective effect on stereotypic behavior on days 7, 14, and 21 as compared to their effect per se in ketamine-treated animals. However, the trend of reduced stereotypic behavior on days 14 and 21 was observed in these combination groups as compared to their treatment alone (Fig. 2).

\section{Effect of hesperidin and coenzyme Q10 on transfer latency in the elevated plus maze (EPM)}

Ketamine $(50 \mathrm{mg} / \mathrm{kg})$ treatment significantly $(p<0.05)$ delayed the transfer latency to move from open arm to close arm in EPM performance task on 1st RTL (day 14) and 2nd RTL (day 21) compared to naïve group of animals. Treatment with hesperidin $(50 \mathrm{mg} / \mathrm{kg}, 100 \mathrm{mg} / \mathrm{kg}$, $200 \mathrm{mg} / \mathrm{kg})$ and coenzyme Q10 (20 mg/kg, $40 \mathrm{mg} / \mathrm{kg})$ were significantly $(p<0.05)$ improved transfer latency on 1st RTL (day 14) and 2nd RTL (day 21) as compared to control (Ketamine treatment). The protective effect of hesperidin $(200 \mathrm{mg} / \mathrm{kg})$ and coenzyme Q10 $(40 \mathrm{mg} /$ $\mathrm{kg}$ ) were comparable to that of olanzapine $(5 \mathrm{mg} / \mathrm{kg})$ treatment in ketamine-treated animals. Further, the combination of hesperidin $(100 \mathrm{mg} / \mathrm{kg})$ with coenzyme Q10 (40 mg/kg) and or hesperidin $(100 \mathrm{mg} / \mathrm{kg})+$ coenzyme Q10 $(40 \mathrm{mg} / \mathrm{kg})+$ olanzapine $(5 \mathrm{mg} / \mathrm{kg})$ did not produce any significant protective effect on EPM performance task (Transfer latency) on 1st RTL (day 14) and 2nd RTL (day 21) as compared to their effect per se in ketamine-treated animals. However, the trend of their effect was observed (Figs. 3, 4).

\section{Effect of hesperidin and coenzyme Q10 on immobility duration using forced swim test}

Ketamine $(50 \mathrm{mg} / \mathrm{kg})$ treatment significantly $(p<0.05)$ increased the immobility duration (despair behavior) in the forced swim test on day 21 compared to the naïve group. Treatment with hesperidin $(50 \mathrm{mg} / \mathrm{kg}$, $100 \mathrm{mg} / \mathrm{kg}, 200 \mathrm{mg} / \mathrm{kg})$ and coenzyme Q10 $(20 \mathrm{mg} / \mathrm{kg}$ and $40 \mathrm{mg} / \mathrm{kg})$ significantly $(p<0.05)$ improved mobility period (decreased immobility duration) on day 21 in ketamine-treated animals. The protective effect of hesperidin $(100 \mathrm{mg} / \mathrm{kg}$ and $200 \mathrm{mg} / \mathrm{kg})$ was comparable to that of olanzapine $(5 \mathrm{mg} / \mathrm{kg}$ ) treatment in ketamine-treated animals. Further, the combination of hesperidin $(100 \mathrm{mg} / \mathrm{kg})$ with coenzyme Q10 $(40 \mathrm{mg} / \mathrm{kg})$ and hesperidin $(100 \mathrm{mg} / \mathrm{kg})+$ coenzyme Q10 (40 mg/ $\mathrm{kg})+$ olanzapine $(5 \mathrm{mg} / \mathrm{kg})$ did not any produce a significant protective effect on immobility period as compared to their per se effect in ketamine-treated animals. However, the trend of further reduced immobility on day 21 has been observed in these combination groups compared to their treatment alone in ketamine-treated animals (Fig. 5).

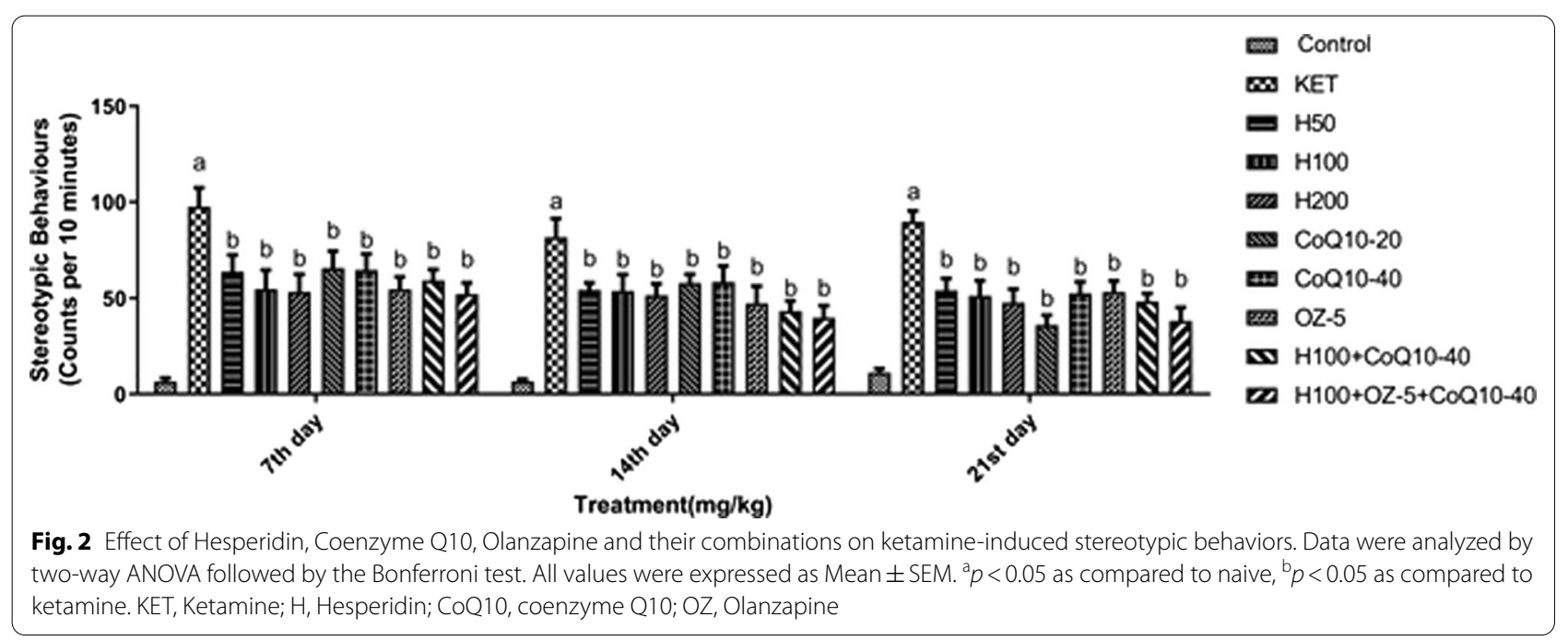




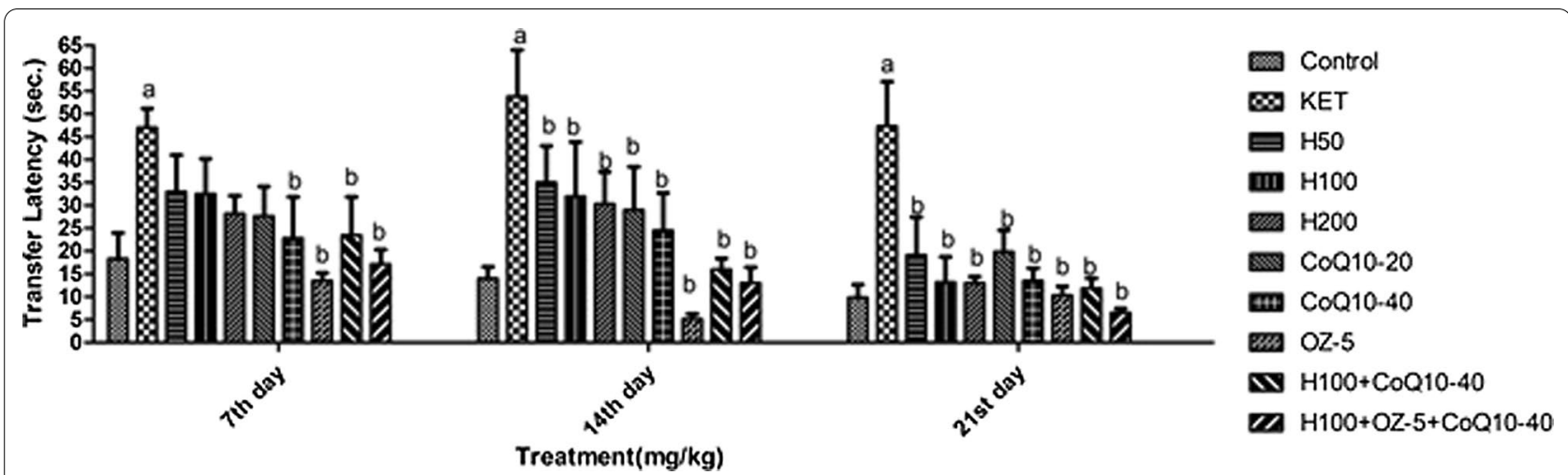

Fig. 3 Effect of hesperidin, coenzyme Q 10 and their combinations elevated performance task. IAL =Initial Acquisition Latency, 1st RTL= First Retention transfer latency, 2nd RTL = Second Retention transfer latency. Data were analyzed by two-way ANOVA followed by the Bonferroni test. All values were expressed as Mean \pm SEM. ${ }^{a} p<0.05$ as compared to naive, ${ }^{b} p<0.05$ as compared to ketamine. KET, Ketamine; $\mathrm{H}, \mathrm{Hesperidin;} \mathrm{CoQ10,}$ Coenzyme Q10; OZ, Olanzapine

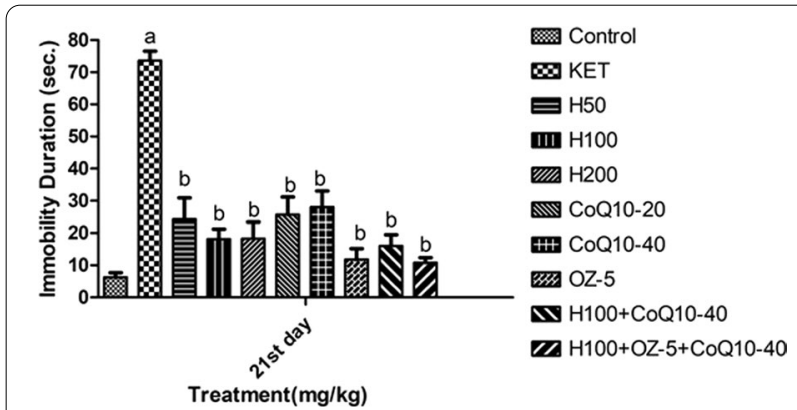

Fig. 4 Effect of Hesperidin, Coenzyme Q10 and their combinations on immobility time. Data were analyzed by two-way ANOVA followed by the Bonferroni test. All values were expressed as Mean \pm SEM. ${ }^{a} p<0.05$ as compared to naive, ${ }^{b} p<0.05$ as compared to ketamine. KET, Ketamine; H, Hesperidin; CoQ10, Coenzyme Q10; OZ, Olanzapine

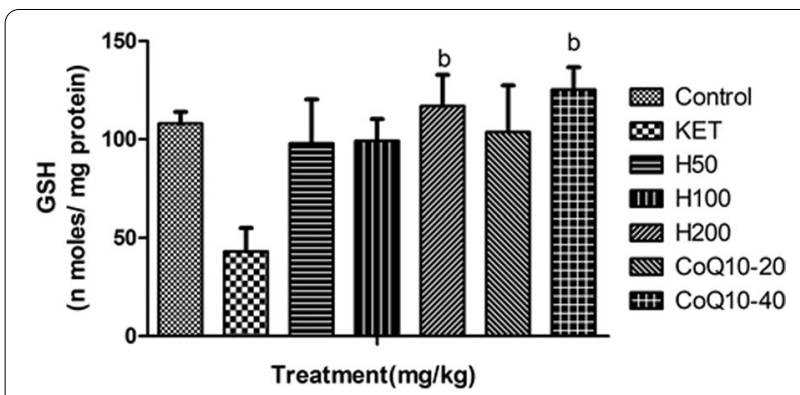

Fig. 5 Effect of Hesperidin and Coenzyme Q10 on GSH levels in the prefrontal cortex regions of the brain. Data were analyzed by one-way ANOVA followed by Tukey's post hoc analysis. All values were expressed as Mean \pm SEM. ${ }^{a} p<0.05$ as compared to naive, ${ }^{b} p<0.05$ as compared to ketamine. KET, Ketamine; H, Hesperidin; CoQ10, Coenzyme Q10

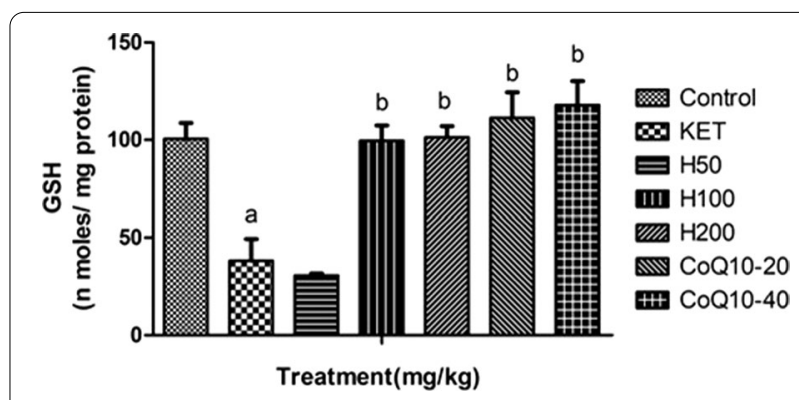

Fig. 6 Effect of Hesperidin and Coenzyme Q10 on GSH levels in the hippocampus regions of the brain. Data were analyzed by one-way ANOVA followed by Tukey's post hoc analysis. All values were expressed as Mean \pm SEM. ${ }^{a} p<0.05$ as compared to naive, ${ }^{b} p<0.05$ as compared to ketamine. KET, Ketamine; H, Hesperidin; CoQ10, Coenzyme Q10

\section{Biochemical estimations \\ Effect of hesperidin and coenzyme $Q 10$ on reduced glutathione (GSH) level in the prefrontal cortex} and hippocampus areas of the ketamine-treated animals

Prefrontal Cortex-Ketamine $(50 \mathrm{mg} / \mathrm{kg})$ treatment for 21 days significantly $(p<0.05)$ depleted reduced glutathione (GSH) level in the prefrontal cortex as compared to the naive group. 21 days treatment with hesperidin $(200 \mathrm{mg} / \mathrm{kg})$ and coenzyme $(40 \mathrm{mg} / \mathrm{kg})$ significantly $(p<0.05)$ restored the glutathione level in the prefrontal cortex as compared to the ketamine group (Fig. 5). However, hesperidin $(50 \mathrm{mg} / \mathrm{kg}$ and $100 \mathrm{mg} / \mathrm{kg})$ and coenzyme Q10 $(20 \mathrm{mg} / \mathrm{kg})$ did not influence significantly $(p<0.05)$ glutathione levels in the prefrontal cortex as compared to the ketamine group.

Hippocampus-Ketamine $(50 \mathrm{mg} / \mathrm{kg})$ treatment for 21 days significantly $(p<0.05)$ depleted GSH in the hippocampus region as compared to the naive group. 21 days treatment with hesperidin $(100 \mathrm{mg} / \mathrm{kg}$ and 
$200 \mathrm{mg} / \mathrm{kg}$ ) and coenzyme Q10 (20 mg/kg and $40 \mathrm{mg} /$ $\mathrm{kg})$ significantly $(p<0.05)$ restored the glutathione level in the hippocampus as compared to the ketamine group. However, hesperidin $(50 \mathrm{mg} / \mathrm{kg})$ did not influence significantly glutathione levels in the hippocampus as compared to the ketamine group (Fig. 6).

\section{Effect of hesperidin and coenzyme Q10 on catalase activity in the prefrontal cortex and hippocampus areas of the ketamine-treated animals}

Prefrontal Cortex-Ketamine $(50 \mathrm{mg} / \mathrm{kg})$ treatment for 21 days significantly $(p<0.05)$ depleted catalase activity in the prefrontal cortex as compared to the naive group. 21 days treatment with hesperidin $(50-200 \mathrm{mg} / \mathrm{kg})$ and coenzyme Q10 $(20,40 \mathrm{mg} / \mathrm{kg})$ significantly $(p<0.05)$ restored the catalase activity as compared to the ketamine group (Fig. 7).

Hippocampus-Ketamine $(50 \mathrm{mg} / \mathrm{kg})$ treatment for 21 days significantly $(p<0.05)$ depleted catalase activity in the hippocampus as compared to the naivve group. 21 days treatment with hesperidin (100 and $200 \mathrm{mg} / \mathrm{kg}$ ) and coenzyme Q10 (20mgkg and $40 \mathrm{mg} / \mathrm{kg}$ ) significantly $(p<0.05)$ restored the catalase activity in the hippocampus as compared to the ketamine group. However, hesperidin $(50 \mathrm{mg} / \mathrm{kg})$ did not influence significantly catalase activity in the hippocampus as compared to the ketamine group (Fig. 8).

\section{Effect of hesperidin and coenzyme Q10 on superoxide dismutase (SOD) activity in the prefrontal cortex and hippocampus areas of the ketamine-treated animals} Prefrontal Cortex-Ketamine $(50 \mathrm{mg} / \mathrm{kg})$ treatment for 21 days significantly $(p<0.05)$ decreased SOD activity in the prefrontal cortex as compared to the naïve group. 21 days treatment with hesperidin $(200 \mathrm{mg} / \mathrm{kg})$ and coenzyme Q10 $(40 \mathrm{mg} / \mathrm{kg})$ significantly $(p<0.05)$ restored

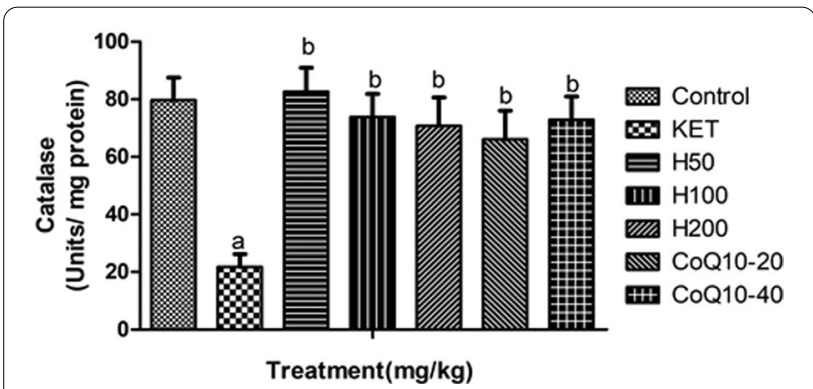

Fig. 7 Effect of hesperidin and Coenzyme Q10 on brain catalase levels in the prefrontal cortex region of the brain. Data were analyzed by one-way ANOVA followed by Tukey's post hoc analysis. All values were expressed as Mean \pm SEM. ${ }^{a} p<0.05$ as compared to naive, $\mathrm{b}_{p}<0.05$ as compared to ketamine. KET, Ketamine; $\mathrm{H}$, Hesperidin; CoQ10, Coenzyme Q10
SOD activity in the prefrontal cortex as compared to ketamine (Fig. 9). However, hesperidin $(50 \mathrm{mg} / \mathrm{kg}$ and $100 \mathrm{mg} / \mathrm{kg})$ and coenzyme Q10 (20 mg/kg) did not influence significantly SOD activity in the prefrontal cortex as compared to the ketamine group.

Hippocampus-Ketamine $(50 \mathrm{mg} / \mathrm{kg})$ treatment for 21 days significantly $(p<0.05)$ decreased SOD activity in the hippocampus as compared to the naïve group. 21 days treatment with hesperidin $(100 \mathrm{mg} / \mathrm{kg}, 200 \mathrm{mg} /$ $\mathrm{kg})$ and coenzyme Q10 $(20 \mathrm{mg} / \mathrm{kg}$ and $40 \mathrm{mg} / \mathrm{kg})$ significantly $(p<0.05)$ restored SOD activity in the hippocampus as compared to control. However, hesperidin $(50 \mathrm{mg} /$ $\mathrm{kg}$ ) did not influence significantly SOD activity in the hippocampus as compared to the ketamine group (Fig. 10).

\section{Mitochondrial estimations}

Effect of hesperidin and coenzyme Q10 on mitochondrial complex I (NADH dehydrogenase) activity

Ketamine $(50 \mathrm{mg} / \mathrm{kg})$ treatment for 21 days significantly $(p<0.05)$ impaired the complex I activity in both
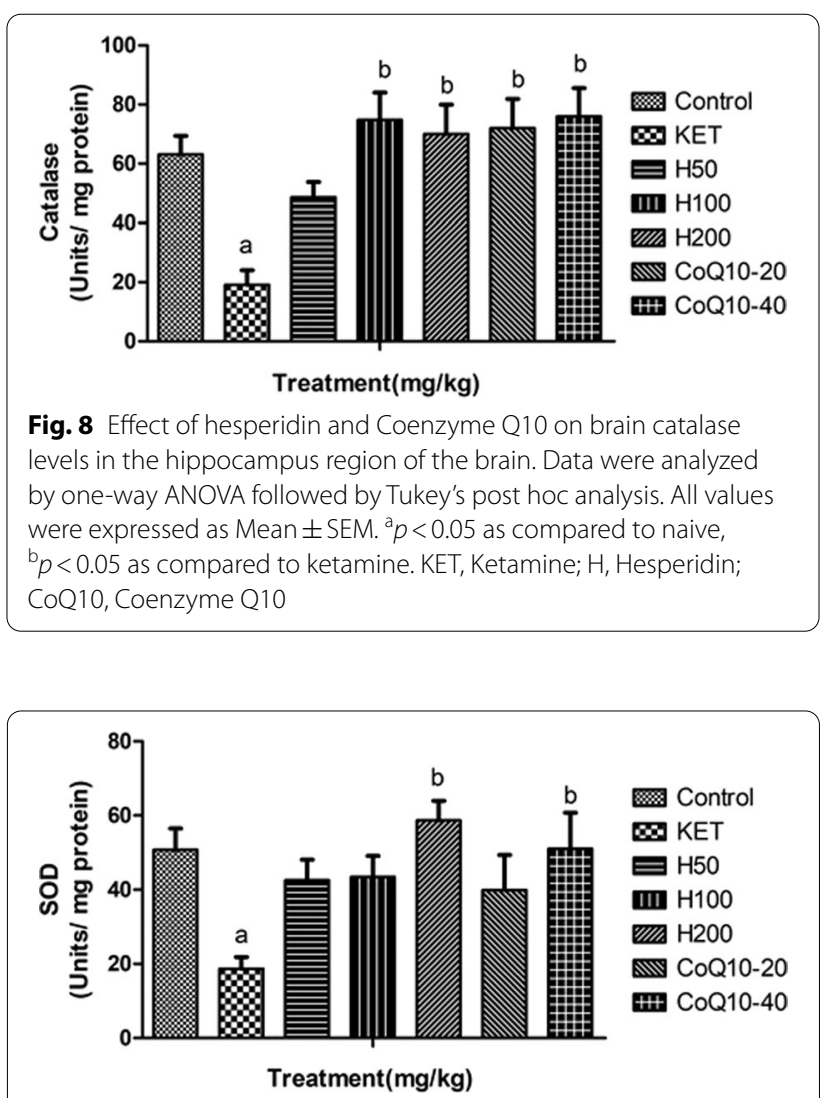

Fig. 9 Effect of hesperidin and Coenzyme Q10 on brain SOD levels in the prefrontal cortex and hippocampus region of the brain. Data were analyzed by one-way ANOVA followed by Tukey's post hoc analysis. All values were expressed as Mean \pm SEM. ${ }^{a} p<0.05$ as compared to naive, ${ }^{b} p<0.05$ as compared to ketamine. KET, Ketamine; H, Hesperidin; CoQ10, Coenzyme Q10 


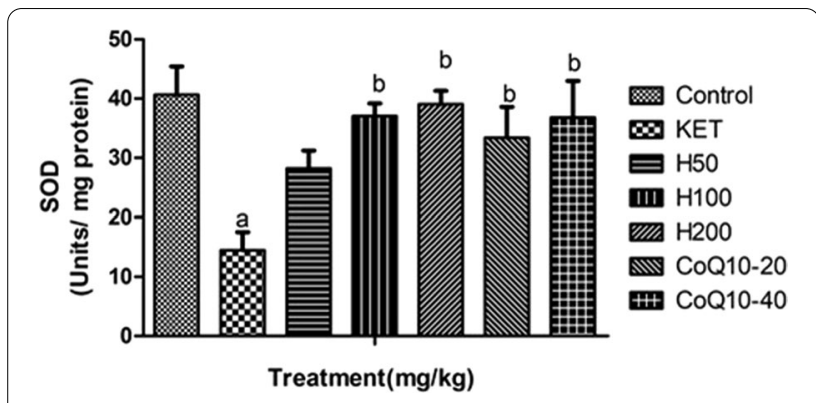

Fig. 10 Effect of hesperidin and Coenzyme Q10 on brain SOD levels in the hippocampus region of the brain. Data were analyzed by one-way ANOVA followed by Tukey's post hoc analysis. All values were expressed as Mean \pm SEM. ${ }^{a} p<0.05$ as compared to naive, ${ }^{b} p<0.05$ as compared to ketamine. KET, Ketamine; $H$, Hesperidin; CoQ10, Coenzyme Q10

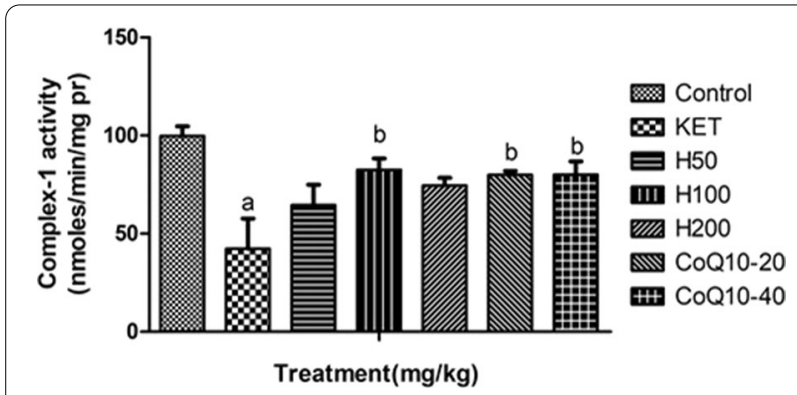

Fig. 11 Effect of hesperidin and Coenzyme Q10 on complex I enzyme activity in the prefrontal cortex region of the brain. Data were analyzed by one-way ANOVA followed by Tukey's post hoc analysis. All values were expressed as Mean \pm SEM. ${ }^{a} p<0.05$ as compared to naive, ${ }^{b} p<0.05$ as compared to ketamine. KET, Ketamine; $H$, Hesperidin; CoQ10, Coenzyme Q10

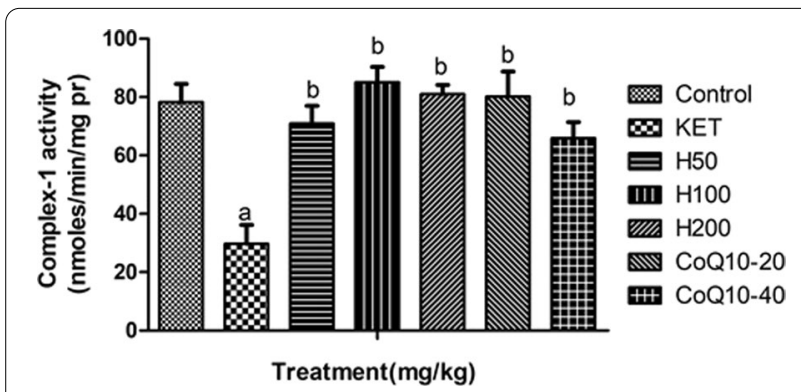

Fig. 12 Effect of hesperidin and Coenzyme Q10 on complex I enzyme activity in the hippocampus region of the brain. Data were analyzed by one-way ANOVA followed by Tukey's post hoc analysis. All values were expressed as Mean $\pm \mathrm{SEM}$. ${ }^{\mathrm{a}} p<0.05$ as compared to naive, ${ }^{b} p<0.05$ as compared to ketamine. KET, Ketamine; $H$, Hesperidin; CoQ10, Coenzyme Q10

prefrontal cortex and hippocampus regions as compared to the naïve group. Further, treatment with hesperidin $(100 \mathrm{mg} / \mathrm{kg})$ and coenzyme Q10 (20 and $40 \mathrm{mg} / \mathrm{kg}$ ) for

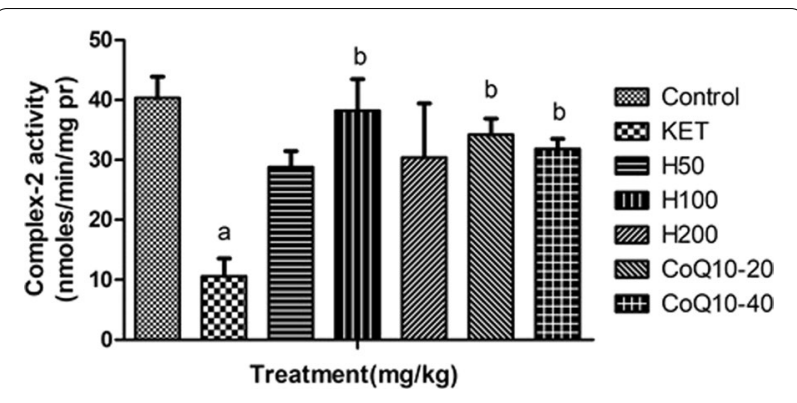

Fig. 13 Effect of hesperidin and Coenzyme Q10 on complex II enzyme activity in the prefrontal cortex region of the brain. Data were analyzed by one-way ANOVA followed by Tukey's post hoc analysis. All values were expressed as Mean \pm SEM. ${ }^{a} p<0.05$ as compared to naive, ${ }^{b} p<0.05$ as compared to ketamine. KET, Ketamine; $H$, Hesperidin; CoQ10, Coenzyme Q10

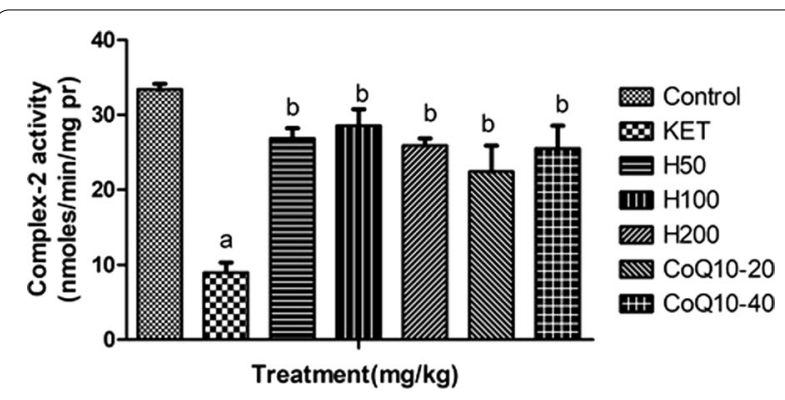

Fig. 14 Effect of hesperidin and Coenzyme Q10 on complex II enzyme activity in the hippocampus region of the brain. Data were analyzed by one-way ANOVA followed by Tukey's post hoc analysis. All values were expressed as Mean \pm SEM. ${ }^{a} p<0.05$ as compared to naive, ${ }^{b} p<0.05$ as compared to ketamine. KET, Ketamine, $\mathrm{H}$, Hesperidin, CoQ10, Coenzyme Q10

21 days significantly $(p<0.05)$ restored Complex I activity in both the prefrontal cortex (Fig. 11) and hippocampus region (Fig. 12) as compared to ketamine group. However, treatment with hesperidin $(50,200 \mathrm{mg} / \mathrm{kg})$ for 21 days did not produce any significant effect on Complex I activity in the prefrontal region as compared to the ketamine group.

\section{Effect of hesperidin and coenzyme Q10 on mitochondrial complex II (Succinate dehydrogenase) activity}

Ketamine $(50 \mathrm{mg} / \mathrm{kg})$ treatment for 21 days significantly $(p<0.05)$ impaired the complex II activity in both prefrontal cortex and hippocampus regions as compared to the naïve group. Further, treatment with hesperidin $(100 \mathrm{mg} / \mathrm{kg})$ and coenzyme Q10 (20 and $40 \mathrm{mg} / \mathrm{kg}$ ) for 21 days significantly $(p<0.05)$ restored Complex II (Succinate dehydrogenase) activity in both the prefrontal cortex (Fig. 13) and hippocampus region (Fig. 14) as compared to ketamine group. However, treatment with hesperidin $(50,200 \mathrm{mg} / \mathrm{kg}$ ) for 21 days did not produce 


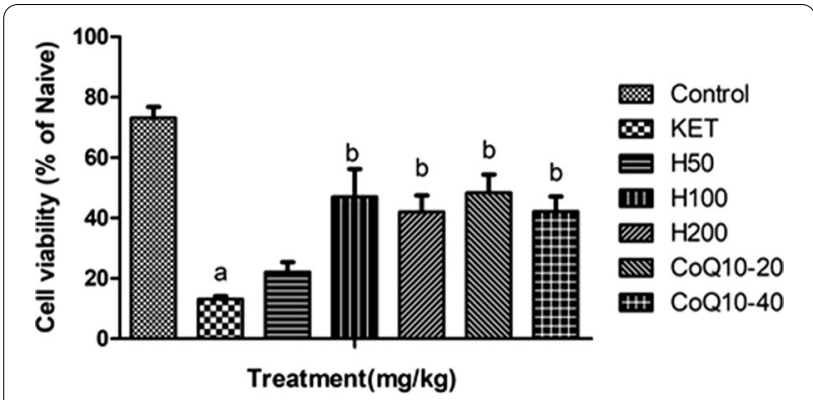

Fig. 15 Effect of hesperidin and Coenzyme Q10 on complex III enzyme (cell viability assay or MTT assay) activity in the prefrontal cortex region of the brain. Data were analyzed by one-way ANOVA followed by Tukey's post hoc analysis. All values were expressed as Mean \pm SEM. ${ }^{a} p<0.05$ as compared to naive, ${ }^{b} p<0.05$ as compared to ketamine. KET, Ketamine; H, Hesperidin; CoQ10, Coenzyme Q10

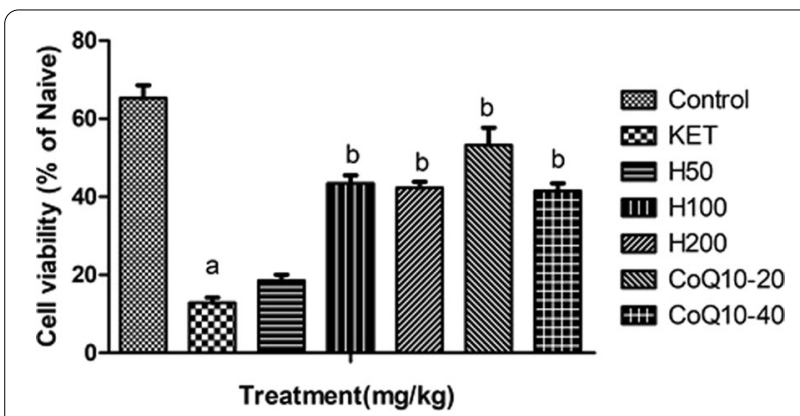

Fig. 16 Effect of hesperidin and Coenzyme Q10 on complex III enzyme (cell viability assay or MTT assay) activity in the hippocampus region of the brain. Data were analyzed by one-way ANOVA followed by Tukey's post hoc analysis. All values were expressed as Mean \pm SEM. ${ }^{a} p<0.05$ as compared to naive, ${ }^{b} p<0.05$ as compared to ketamine. KET, Ketamine; H, Hesperidin; CoQ10, Coenzyme Q10

any significant effect on Complex II activity in the prefrontal region as compared to the ketamine group (Fig. 13).

\section{Effect of hesperidin and coenzyme Q10 on mitochondrial complex III (MTT assay) activity}

Ketamine $(50 \mathrm{mg} / \mathrm{kg})$ treatment for 21 days significantly $(p<0.05)$ impaired the complex III activity in both prefrontal cortex and hippocampus regions as compared to the naïve group. Further, treatment with hesperidin (100 and $200 \mathrm{mg} / \mathrm{kg}$ ) and coenzyme Q10 (20 and $40 \mathrm{mg} / \mathrm{kg})$ for 21 days significantly $(p<0.05)$ restored complex III activity in both the prefrontal cortex (Fig. 15) and hippocampus region (Fig. 16) as compared to ketamine group. However, treatment with hesperidin $(50 \mathrm{mg} / \mathrm{kg})$ for 21 days did not produce any significant effect on complex III in both the prefrontal and hippocampus region as compared to the ketamine group.

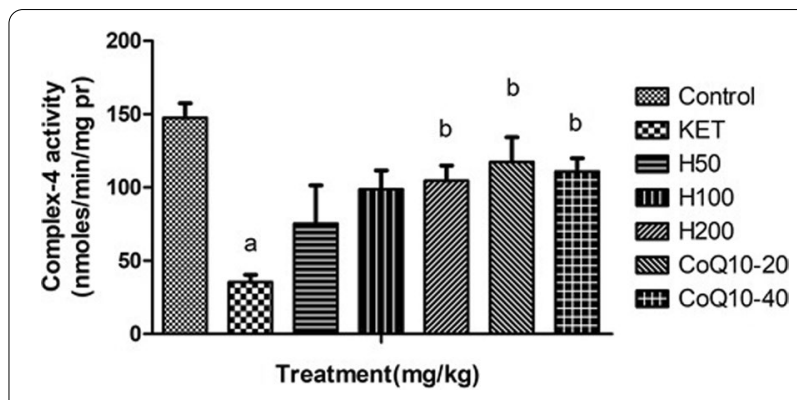

Fig. 17 Effect of hesperidin and Coenzyme Q10 on complex IV enzyme activity in the prefrontal cortex region of the brain. Data were analyzed by one-way ANOVA followed by Tukey's post hoc analysis. All values were expressed as Mean \pm SEM. ${ }^{a} p<0.05$ as compared to naive, ${ }^{b} p<0.05$ as compared to ketamine. KET, Ketamine; $H$, Hesperidin; CoQ10, Coenzyme Q10

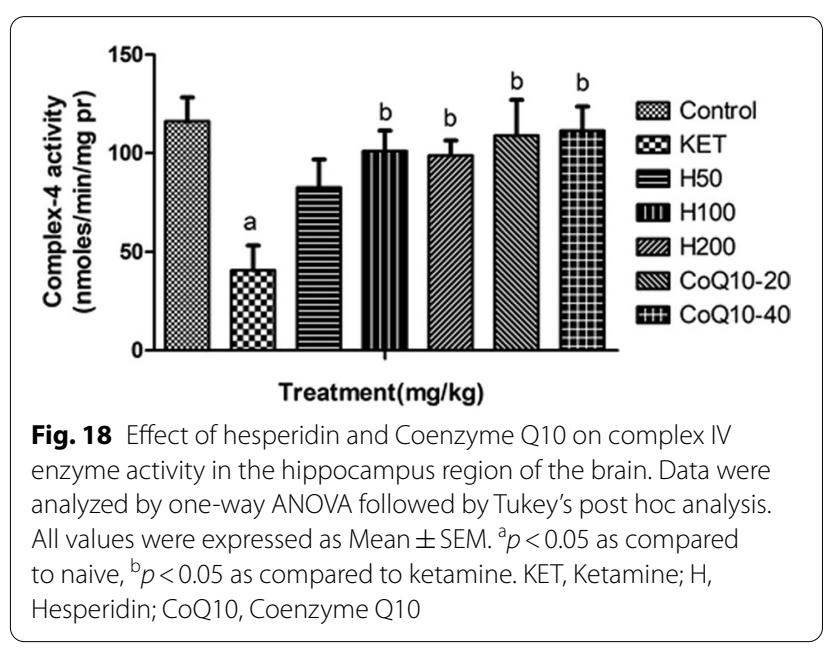

\section{Effect of hesperidin and coenzyme Q10 on mitochondrial complex IV (Cytochrome oxidase) activity}

Ketamine $(50 \mathrm{mg} / \mathrm{kg})$ treatment for 21 days significantly $(p<0.05)$ decreased complex IV activity in both the prefrontal cortex and hippocampus region of the brain, as compared to the naïve group. Further, treatment with hesperidin $(200 \mathrm{mg} / \mathrm{kg})$ and coenzyme Q10 $(20$ and $40 \mathrm{mg} / \mathrm{kg})$ for 21 days significantly $(p<0.05)$ restored complex IV activity prefrontal cortex (Fig. 17) as compared to the ketamine group. Similarly, treatment with hesperidin (100 and $200 \mathrm{mg} / \mathrm{kg}$ ) and coenzyme Q10 (20 and $40 \mathrm{mg} / \mathrm{kg}$ ) for 21 days significantly $(p<0.05)$ restored activity complex IV in the hippocampus (Fig. 18) as compared to the ketamine group. However, treatment with hesperidin $(50 \mathrm{mg} / \mathrm{kg})$ for 21 days did not produce any significant effect on complex IV activity in both the prefrontal cortex and hippocampus region as compared to the ketamine group. 


\section{Discussion}

Studies have shown that antagonists of NMDA-Rs, such as ketamine and MK-801, induce behavioral changes (positive symptoms, negative symptoms, and cognitive decline) $[7,8,19]$. In this study, ketamine administration developed both positive and negative symptoms along with cognitive deficits in mice. Ketamine administration significantly increased locomotor activity on days 7 and 14 followed by hypolocomotion on day 21 of the experiment and induced stereotypic behaviors indicative of positive symptoms of psychosis. Negative symptoms in ketamine-treated animals were represented by increased immobility duration in the forced swim test. Moreover, ketamine treatment significantly caused cognitive deficit as evidenced by delayed transfer latency in the closed arm of elevated plus maze performance task on days 14 and 21 . There are consistent observations that have showed to induce positive symptoms, negative symptoms, and cognitive decline in animals $[8,30]$, supporting our study.

In this study, 21 days of administration of hesperidin and CoQ 10 significantly reversed both positive and negative symptoms along with cognitive improvement in ketamine-treated animals suggesting their protective effects. The study further validates the previous reports on psychosis $[8,29]$. Furthermore, the combination of hesperidin $(100 \mathrm{mg} / \mathrm{kg})$ with CoQ $10(40 \mathrm{mg} / \mathrm{kg})$ did not produce any significant protective effect on hyperlocomotor activity on days 7 and 14 and hypolocomotor activity on day 21 as compared to their per se effect in ketamine-treated animals. However, in the combination group, the trend of reduced locomotor activity on days 7 and 14 and increased locomotor activity on day 21 was observed as compared to their treatment alone. Furthermore, the positive trend of their protective effect indicates that their combination in higher doses could be effective. Whereas, the combination of hesperidin $(100 \mathrm{mg} / \mathrm{kg})$, CoQ $10(40 \mathrm{mg} / \mathrm{kg})$ with olanzapine $(5 \mathrm{mg} / \mathrm{kg})$ significantly reversed ketamine-induced hyperlocomotion on days 7 and 14 which showed that olanzapine might have some positive synergism in causing their protective effect in ketamine-treated animals. This study suggested that hesperidin and CoQ 10 combination could be useful as an adjuvant in enhancing the protective effect of olanzapine against ketamine-induced psychosis.

Administration of hesperidin and CoQ 10 for 21 days significantly reversed ketamine-produced stereotypic behavior on days 7,14 , and 21 . The effect of hesperidin was similar to olanzapine $(5 \mathrm{mg} / \mathrm{kg})$ effects in ketaminetreated animals. Furthermore, the combination of hesperidin $(100 \mathrm{mg} / \mathrm{kg})$ with CoQ $10(40 \mathrm{mg} / \mathrm{kg})$ and or a combination of hesperidin $(100 \mathrm{mg} / \mathrm{kg})$ with CoQ 10 $(40 \mathrm{mg} / \mathrm{kg})$ and olanzapine $(5 \mathrm{mg} / \mathrm{kg})$ was not any significant effect on stereotypic behaviors on days 7,14 , and
21 as compared to their per se effect in ketamine-treated animals. Treatment with hesperidin and CoQ 10 significantly improved transfer latency. Moreover, the combination of hesperidin $(100 \mathrm{mg} / \mathrm{kg})$ with CoQ $10(40 \mathrm{mg} /$ $\mathrm{kg})$ and or hesperidin $(100 \mathrm{mg} / \mathrm{kg})$ with CoQ 10 (40 mg/ $\mathrm{kg}$ ) and olanzapine $(5 \mathrm{mg} / \mathrm{kg})$ did not produce any significant protective effect on memory as compared to their per se effect in ketamine-treated animals. Treatment with hesperidin and CoQ 10 significantly improved the mobility period in ketamine-treated animals. The combination of hesperidin $(100 \mathrm{mg} / \mathrm{kg})$ with CoQ $10(40 \mathrm{mg} /$ $\mathrm{kg})$ and hesperidin $(100 \mathrm{mg} / \mathrm{kg})$ with CoQ $10(40 \mathrm{mg} / \mathrm{kg})$ and olanzapine $(5 \mathrm{mg} / \mathrm{kg})$ did not any produce a significant protective effect on immobility period as compared to their per se effect in ketamine-treated animals. These results were comparable to that of olanzapine treatment in ketamine-treated animals, which represents that hesperidin and CoQ10 might follow the same mechanism of action as olanzapine.

Flavonoids administration has been associated with delayed onset and development, decreased risk, or increased improvement of various neuropsychiatric disorders [31]. Many pharmacological investigations suggested the neuroprotective role of flavonoids due to their antioxidant, anti-inflammatory, and mitochondrial complex functions restoring property $[32,33]$. This is because of their structural similarity, biochemical specificity, and chemical diversity [19]. Flavonoids have been shown to increase gamma-aminobutyric acid (GABA) concentration [34], which modulates sensitivity to dopaminergic neurotransmissions and thus they have the potential to treat positive symptoms of psychosis. Flavonoids also normalize mood due to antidepressant properties [35]. Many studies suggested the protective effect of flavonoids in learning and memory dysfunction [36-38].

Antioxidant enzyme deficiency and oxidative stress are involved in the pathophysiology of psychosis [39]. Dopamine is a highly redox reactive molecule and generates ROS during normal neurotransmission [40]. Psychotic mice were found to be more prone to oxidative stress as compared to healthy mice $[41,42]$. This difference can be ascribed due to the deficiency of the antioxidant enzyme. NMDA-R-ionophores are reported to be regulated by endogenous glutathione (antioxidant) and slightly activate the glutamate and NMDA-Rs induced calcium influx [43, 44]. Hence, glutathione deficiency is an important factor for the hypofunction of NMDA receptors in psychosis $[45,46]$. These reports suggest that lowering glutathione levels can alter the presynaptic mechanisms involved in neurotransmitter release. Moreover, ketamine (NMDA-R antagonist) has been well documented to deplete GSH levels in the prefrontal cortex, hippocampus, and striatum and contribute to 
the genesis of psychotic behaviors like increased stereotypic gestures, immobility duration, and delayed transfer latency in animals [19]. Furthermore, mitochondrial glutathione (mGSH) entails as a defense to regulate the mitochondrial redox system to prevent oxidative modifications leading to mitochondrial dysfunction and apoptosis. Notably, various preclinical and clinical pieces of evidence reported the potential effect of antioxidant precursor treatment in psychosis [47-49]. In this study, ketamine significantly decreased GSH levels in the hippocampus without influencing its level in the prefrontal cortex. Both hesperidin and CoQ10 treatment for 21 days significantly restored the GSH level hippocampal region suggesting their protective defense action. Their protective effect may be due to their free radical scavenging properties. The results further support the previous reports $[7,19]$. SOD is another enzyme that also helps to fight reactive oxygen species (ROS) [50]. Preclinical and clinical studies on psychosis reported decreased SOD activity in the psychotic patient [51]. Treatment with hesperidin and CoQ 10 reversed endogenous antioxidant SOD activity suggesting their protective effect. Similarly, catalase is also an essential antioxidant enzyme that utilizes oxygen. The development of neurological disorders has also resulted from mutation or deficiency of this enzyme $[42,52]$. The catalase activity was significantly reduced in ketamine-treated animals, which was significantly restored by chronic treatment with hesperidin and CoQ10 in our study, this mechanism might be involved to reduce the psychotic behaviors in the animals.

All functions of the body require energy in the form of adenosine triphosphate (ATP) and this energy is mainly generated in mitochondria by a process called oxidative phosphorylation. Apart from producing ATP and phosphocreatine high energy phosphates mitochondria and oxidative phosphorylation (OXPHOS) also play a vital role in some vital cellular functions and processes including reactive oxygen species production [53], inflammation [54, 55], calcium homeostasis, and apoptotic signaling [56, 57]. Also, OXPHOS dysfunctioning is reported in some neuropsychiatric disorders including psychosis [58, 59]. The significant interaction between mitochondrial respiration and dopamine is proposed to be involved in psychosis. Several studies indicate the involvement of ketamine to impair mitochondrial associated functions $[60,61]$. In the present study, chronic ketamine administration has significantly decreased the activity of mitochondrial complex I, II, III, and IV in the prefrontal cortex and hippocampus regions of the brain. Hesperidin is having ubiquinone property which significantly OXPHOS restored the activity of brain mitochondrial complexes in the present study. Moreover, CoQ 10 was also reported to have ubiquinone properties [62]. It is well known for its mitochondrial restorative property enzymes and improves the neuroprotective effect. Previously, CoQ 10 has shown statistically significant and robust clinical improvements in mitochondrial enzyme in many neuropsychiatric disorders especially cognitive deficient [63]. CoQ 10 effectively improved neuroprotective effects by restoring mitochondrial enzyme complexes activity in this study. However, a combination of hesperidin with CoQ10 has not produced any significant effect in reversing the activity of mitochondrial enzyme complexes as compared to their effect alone but trends were seen with their treatment. This could be due to their independent mode of action. So, the biochemical studies and mitochondrial assays suggested the antioxidant and mitochondrial restoring property of hesperidin and $\mathrm{CoQ} 10$ and due to this these agents were responsible to produce neuroprotective effects against ketamineinduced behavioral changes in mice by restoring the protective defense system. However, a possible hesperidin protective effect can be understood by Fig. 19. So, it can be demonstrated that the antioxidant and mitochondrial properties of hesperidin and CoQ10 reversed the ketamine dysfunctioning brain biological activity. Hence, by following this mechanism hesperidin and CoQ10 significantly reduced positive and negative symptoms and increase cognitive function. The limitation of the study is that neurotransmitters level like dopamine levels can make this research more effective and clear. Otherwise, the results of the study demonstrate that the hesperidin alone or in combination with Coenzyme Q10 would be therapeutically effective in the treatment of human psychiatric disorders or can prove a potential neuroprotective agent.

\section{Conclusions}

The present study concluded that hesperidin and CoQ10 showed potential effects to ameliorate ketamine-induced psychotic behaviors and cognitive decline. The protective effects of hesperidin and $\mathrm{CoQ} 10$ seem to be mediated by potent antioxidant and mitochondrial restoring properties. Furthermore, treatment of hesperidin in combination with CoQ10 potentiated their effects against ketamine-induced psychotic behaviors, which showed its synergistic effects. These results suggest that hesperidin and CoQ10 are the potential candidates to be explored further for the treatment of human psychosis.

\section{Limitation of the study}

More biochemical estimations like dopamine level and AChE activity and histopathological study could have been conducted for more understanding. 


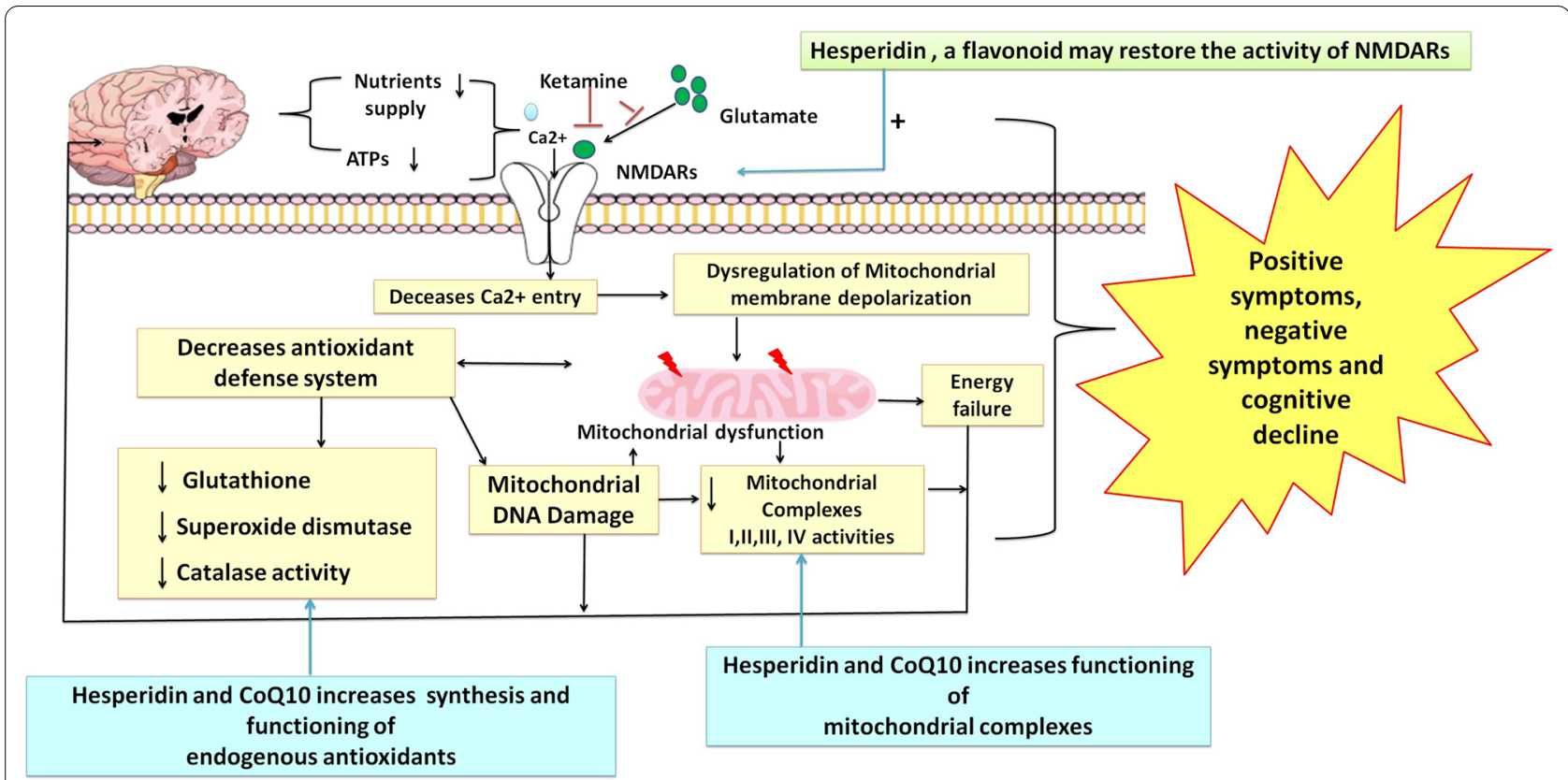

Fig. 19 Possible mechanism of action of hesperidin and CoQ10

\section{Abbreviations}

ANOVA: Analysis of variance; ATP: Adenosine triphosphate; BSA: Bovine serum albumin; cm: Centimeter; CMC: Carboxymethylcellulose; CoQ10: Coenzyme Q10; EGTA: Ethylene glycol-bis( $\beta$-aminoethyl ether)- $N, N, N^{\prime}, N^{\prime}$-tetraacetic acid; ELISA: Enzyme-linked immunosorbent assay; EPM: Elevated plus maze; g: Gram; GABA: Gamma-aminobutyric acid; GSH: Reduced glutathione; HEPES: 4-(2-Hydroxyethyl)-1-piperazineethanesulfonic acid; i.p.: Intraperitoneal; ITL: Initial transfer latency; kg: Kilogram; mg: Milligram; ml: Milliliter; MTT: [3-(4,5-Dimethylthiazol-2-yl)-2,5-diphenyl-H-tetrazolium bromide]; NAD + : Nicotinamide adenine dinucleotide ion; NADH: Nicotinamide adenine dinucleotide; $\mathrm{NaOH}$ : Sodium hydroxide; NMDA-Rs: N-Methyl-D-aspartate receptors; OXPHOS: Oxidative phosphorylation; PNS: Post-nuclear supernatant; p.o.: Peroral; ROS: Reactive oxygen species; RTL: Retention transfer latency; SDH: Succinate dehydrogenase; SEM: Standard error of the mean; SOD: Superoxide dismutase; w/v: Weight/volume.

\section{Acknowledgements}

The authors are thankful to the University Institute of Pharmaceutical Sciences (UIPS), Panjab University Chandigarh, for the infrastructure facilities to carry out this work.

\section{Authors' contributions}

The entire theme and idea of the work were given by MY and AK. Experimental studies were conducted and compiled by NK, MK, and SK. Further, the overall results of the study were analyzed by both NK and MY. Manuscript drafting was done by NK under the supervision of AK. All authors have carefully read and approved the manuscript.

\section{Funding}

The study was financially supported by SERB-DST (New Delhi-India) Letter number PDF/2018/002605. The funding body provided finance for the collection of animals and chemicals used in the present study and analysis and interpretation of data obtained.

\section{Availability of data and materials}

Data and material will be provided upon request.

\section{Declarations}

Ethics approval and consent to participate

The animal protocol was approved by the Institutional Animal Ethics Committee of Panjab University, Chandigarh (PU/45/99/CPCSEA/IAEC/2019/289).

\section{Consent for publication}

Not applicable.

\section{Competing interests}

This paper is jointly prepared by all the authors and there are no conflicts of interest.

Received: 1 June 2021 Accepted: 4 January 2022

Published online: 15 January 2022

\section{References}

1. Aucoin M, Lachance L, Cooley K, Kidd S (2020) Diet and psychosis: a scoping review. Neuropsychobiology 79(1):20-42

2. Parle M, Kadian R (2013) Behavioral models of psychosis. Int Res J Pharm 4:26-30

3. Shao L, Martin MV, Watson SJ, Schatzberg A, Akil H, Myers RM, Jones EG, Bunney WE, Vawter MP (2005) Mitochondrial involvement in psychiatric disorders. Ann Med 40(4):281-295

4. Rajasekaran A, Venkatasubramanian G, Berk M, Debnath M (2015) Mitochondrial dysfunction in schizophrenia: pathways, mechanisms and implications. Neurosci Biobehav Rev 48:10-21

5. Miean KH, Mohamed S (2001) Flavonoid (myricetin, quercetin, kaempferol, luteolin, and apigenin) content of edible tropical plants. J Agric Food Chem 49(6):3106-3112

6. Hwang SL, Shih PH, Yen GC (2012) Neuroprotective effects of citrus flavonoids. J Agric Food Chem 160(4):877-885 
7. Yadav M, Parle M, Sachdeva M, Dhingra S (2017) Standardisation and validation of acute and chronic administration ketamine at different doses to produce psychosis-like behavioural changes in mice. Int J Toxicol Pharmacol Res 9(1):33-38

8. Yadav M, Parle M, Sharma N, Dhingra S, Raina N, Jindal DK (2017) Brain targeted oral delivery of doxycycline hydrochloride encapsulated tween 80 coated chitosan nanoparticles against ketamine-induced psychosis: behavioral, biochemical, neurochemical and histological alterations in mice. Drug Deliv 24(1):1429-1440

9. Rishitha N, Muthuraman A (2018) Therapeutic evaluation of solid lipid nanoparticle of quercetin in pentylenetetrazole induced cognitive impairment of zebrafish. Life Sci 199:80-87

10. Hajialyani M, Farzaei MH, Echeverría J, Nabavi SM, Uriarte E, Eduardo SS (2019) Hesperidin as a neuroprotective agent: a review of animal and clinical evidence. Molecules 24(3):648

11. Singh D, Hembrom S (2018) Neuroprotective effect of flavonoids: a systematic review. Int J Aging Res 2(1):1-17

12. Ayaz M, Sadiq A, Junaid M, Ullah F, Ovais M, Ullah I, Ahmed J, Shahid M (2019) Flavonoids as prospective neuroprotectants and their therapeutic propensity in ageing-associated neurological disorders. Front Aging Neurosci 11:155-169

13. Hasan W, Kori RK, Jain J, Yadav RS, Jat D (2020) Neuroprotective effects of mitochondria-targeted curcumin against rotenone-induced oxidative damage in cerebellum of mice. J Biochem Mol Toxic 34(1):1-8

14. Cyr M, Calon F, Morissette M, Di Paolo T (2002) Estrogenic modulation of brain activity: implications for schizophrenia and Parkinson's disease. J Psychiatry Neurosci 27(1):12-27

15. da Silva FC, de Oliveira Cito MD, da Silva MI, Moura BA, de Aquino Neto MR, Feitosa ML, de Castro CR, Macedo DS, de Vasconcelos SM, de França Fonteles MM, de Sousa FC (2010) Behavioral alterations and pro-oxidant effect of a single ketamine administration to mice. Brain Res Bull 83(1-2):9-15

16. Sharma K, Parle M, Yadav M (2016) Evaluation of antipsychotic effect of methanolic extract of Ocimum sanctum leaves on laboratory animals. J Appl Pharm Sci 6(5):171-177

17. Sharma AC, Kulkarni SK (1992) Evaluation of learning and memory mechanisms employing elevated plus-maze in rats and mice. Prog Neuropsychopharmacol Biol Psychiatry 16(1):117-125

18. Chhillar R, Dhingra D (2013) Antidepressant-like activity of gallic acid in mice subjected to unpredictable chronic mild stress. Fund Clin Pharmacol 27(4):409-418

19. Yadav M, Jindal DK, Dhingra MS, Kumar A, Parle M, Dhingra S (2018) Protective effect of gallic acid in experimental model of ketamineinduced psychosis: possible behaviour, biochemical, neurochemical and cellular alterations. Inflammopharmacology 26(2):413-424

20. Brown MR, Sullivan PG, Dorenbos KA, Modafferi EA, Geddes JW, Steward O (2004) Nitrogen disruption of synaptoneurosomes: an alternative method to isolate brain mitochondria. J Neurosci Methods 137(2):299-303

21. Bradford MM (1976) A rapid and sensitive method for the quantitation of microgram quantities of protein utilizing the principle of proteindye binding. Anal Biochem 72:248-225

22. Ellman GL (1959) Tissue sulfhydryl groups. Arch Biochem Biophys 82(1):70-77

23. Luck H (1971) Catalase in methods of enzymatic analysis (Bergmeyer HU Edn). Academic Press, New York, pp 885-893

24. Kono Y (1978) Generation of superoxide radicals during auto-oxidation of hydroxyl-amine hydrochloride an assay for SOD. Arch Biochem Biophys 186(1):189-195

25. King TE, Howard RL (1967) Preparations and properties of soluble NADH dehydrogenases from cardiac muscle. Methods Enzymol 10:275-294

26. King TE (1967) Preparation of succinate dehydrogenase and reconstitution of succinate oxidase. Methods Enzymol 10:322-331

27. Liu Y, Peterson DA, Kimura H, Schubert D (2002) Mechanism of cellular 3-(4,5-dimethylthiazol-2-yl)-2,5-diphenyltetrazolium bromide (MTT) reduction. J Neurochem 69(2):581-593

28. Sottocasa GL, Kuylenstierna B, Ernster L, Bergstrand A (1967) An electron-transport system associated with the outer membrane of liver mitochondria. A biochemical and morphological study. J Cell Biol 32(20):415-438
29. Chatterjee M, Verma P, Maurya R, Palit G (2011) Evaluation of ethanol leaf extract of ocimum sanctum in experimental models of anxiety and depression. Pharm Biol 49(5):477-483

30. Chatterjee M, Verma R, Ganguly S, Palit G (2012) Neurochemical and molecular characterization of ketamine-induced experimental psychosis model in mice. Neuropharmacology 63(6):1161-1171

31. Dajas F, Rivera-Megret A, Blasina F, Arrendondo F, Abin-Carriquiry JA, Costa G (2003) Neuroprotection by flavonoids. Braz J Med Biol Res 36(12):1613-1620

32. Pietta PG (2000) Flavonoids as antioxidants. J Nat Prod 63(7):1035-1042

33. Lagoa R, Graziani I, Lopez-Sanchez C, Garcia-Martinez V, Gutierrez-Merino C (2011) Complex I and cytochrome-C are molecular targets of flavonoids that inhibit hydrogen peroxide production by mitochondria. BBA-Bioenergetics 1807(12):1562-1572

34. Hanrahan JR, Chebib M, Johnston GAR (2011) Flavonoid modulation of GABA-A receptors. Br J Pharmacol 163(2):234-245

35. Khan H, Perviz S, Sureda A, Nabavi SM, Tejada S (2018) Current standing of plant derived flavonoids as an antidepressant. Food Chem Toxicol 119:176-188

36. Spencer JPE (2013) Flavonoids: modulators of brain function? Brit J Nutr 99(E-S1):60-77

37. Spencer JPE (2014) The impact of flavonoids on memory: physiological and molecular considerations. Chem Soc Rev 38(4):1152-1161

38. Vauzour D (2014) Effect of flavonoids on learning, memory and neurocognitive performance: relevance and potential implications for Alzheimer's disease pathophysiology. J Sci Food Agric 94(6):1042-1056

39. Barron H, Hafizi S, Andreazza AC, Mizrahi R (2017) Neuroinflammation and oxidative stress in psychosis and psychosis risk. Int J Mol Sci 18(3):651-664

40. Grima G, Benz B, Parpura V, Cuenod M, Do KQ (2003) Dopamine-induced oxidative stress in neurons with glutathione deficit: implication for schizophrenia. Schizophr Res 62(3):213-224

41. Sorce S, Schiavone S, Tucci P, Colaianna M, Jaquet V, Cuomo V (2010) The NADPH oxidase NOX 2 controls glutamate release: a novel mechanism involved in psychosis-like ketamine responses. J Neurosci 30(34):11317-11325

42. Fraguas D, Díaz-Caneja CM, Rodríguez-Quiroga A, Arango C (2017) Oxidative stress and inflammation in early onset first episode psychosis: a systematic review and meta-analysis. Int J Neuropsychoph 20(5):435-444

43. Varga V, Jenaei Z, Janáky R, Saransaari P, Oja SS (1997) Glutathione is an endogenous ligand of rat brain $\mathrm{N}$-methyl-D-aspartate (NMDA) and 2-amino-3-hydroxy-5-methyl-4-isoxazolepropionate (AMPA) receptors. Neurochem Res 22(9):1165-1171

44. Wallin C, Weber SG, Sandberg M (1998) Glutathione efflux induced by NMDA and kainate: implications in neurotoxicity? I Neurochem 73(4):1566-1572

45. Dean O, den Buuse M, Bush Al, Copolov DL, Ng F, Dodd S, Berk M (2009) A role for glutathione in the pathophysiology of bipolar disorder and schizophrenia? Animal models and relevance to clinical practice. Curr Med Chem 16(23):2965-2976

46. Nucifora LG, Tanaka T, Hayes LN, Kim M, Lee BJ, Matsuda T (2017) Reduction of plasma glutathione in psychosis associated with schizophrenia and bipolar disorder in translational psychiatry. Transl Psychiatry 7(8):e1215

47. Hussain S, Slikker W, Ali SF (1995) Age-related changes in antioxidant enzymes, superoxide dismutase, catalase, glutathione peroxidase and glutathione in different regions of mouse brain. Int J Dev Neurosci 13(8):811-817

48. Conus P, Fournier M, Xin L, Baumann P, Ferrari C, Cousins A et al (2017) $\mathrm{N}$-acetyl-cysteine in a double-blind randomized placebo-controlled trial: towards biomarker-guided treatment in early psychosis. Eur Psychiatry 44(2):s806-5806

49. Schiavone S, Trabace L (2018) The use of antioxidant compounds in the treatment of first psychotic episode: highlights from preclinical studies. CNS Neurosci Ther 24(6):465-472

50. Keller JN, Kindy MS, Holtsberg FW, St. Clair DK, Yen HC, Germeyer A et al (1998) Mitochondrial manganese superoxide dismutase prevents neural apoptosis and reduces ischemic brain injury: suppression of peroxynitrite production, lipid peroxidation, and mitochondrial dysfunction. J Neurosci 18(2):687-697 
51. Martínez-Cengotitabengoa M, Mac-Dowell KS, Leza JC, Mico JA, Fernandez M, Echevarría E, Sanjuan J, Julian E, Gonzalez-Pinto A (2012) Cognitive impairment is related to oxidative stress and chemokine levels in first psychotic episodes. Schizophr Res 137(1-3):66-72

52. Evans DR, Parikh VV, Khan MM, Coussons C, Buckley PF, Mahadik SP (2003) Red blood cell membrane essential fatty acid metabolism in early psychotic patients following antipsychotic drug treatment. Prostag Leukotr Ess 69(6):393-399

53. Acin-Perez R, Salazar E, Kamenetsky M, Buck J, Levin LR, Manfredi G (2009) Cyclic AMP produced inside mitochondria regulates oxidative phosphorylation. Cell Metab 9(3):265-276

54. Seth RB, Sun L, Ea CK, Chen ZJ (2005) Identification and characterization of MAVS, a mitochondrial antiviral signaling protein that activates NF-KB and IRF3. Cell 122(5):669-682

55. Ricci JE, Munoz-Pinedo C, Fitzgerald P, Bailly-Maitre B, Perkins GA, Yadava N (2004) Disruption of mitochondrial function during apoptosis is mediated by caspase cleavage of the p75 subunit of complex I of the electron transport chain. Cell 117(6):773-786

56. Valsecchi F, Ramos-Espiritu LS, Buck J, Levin LR, Manfredi G (2009) CAMP and mitochondria. Physiology 28(3):199-209

57. Wallace DC (1999) Mitochondrial diseases in man and mouse. Science 283(5407):1482-1488

58. Fattal O, Budur K, Vaughan AJ, Franco K (2006) Review of the literature on major mental disorders in adult patients with mitochondrial diseases. Psychosomatics 47(1):1-7

59. De Oliveira L, Fraga DB, De Luca RD, Canever L, Ghedim FV, Matos MP, Streck EL, Quevedo J, Zugno Al (2011) Behavioral changes and mitochondrial dysfunction in a rat model of schizophrenia induced by ketamine. Metab Brain Dis 26(1):69-77

60. Robinson BL, Dumas M, Ali SF, Paule MG, Gu Q, Kanungo J (2018) Mechanistic studies on ketamine-induced mitochondrial toxicity in zebrafish embryos. Neurotoxicol Teratol 69:63-72

61. Takada M, Ikenoya S, Yuzuriha T, Katayama K (1982) Studies on reduced and oxidized coenzyme Q (ubiquinones) II. The determination of oxidation-reduction levels of coenzyme $\mathrm{Q}$ in mitochondria, microsomes and plasma by high-performance liquid chromatography. BBA-Bioenergetics 679(2):308-314

62. Monsef A, Shahidi S, Komaki A (2019) Influence of chronic coenzyme Q10 supplementation on cognitive function, learning and memory in healthy and diabetic middle-aged rats. Neuropsychobiology 77(2):92-100

63. Hüttemann M, Helling S, Sanderson TH, Sinkler C, Samavati L, Mahapatra $\mathrm{G}$ et al (2012) Regulation of mitochondrial respiration and apoptosis through cell signaling: cytochrome c oxidase and cytochrome $c$ in ischemia/reperfusion injury and inflammation. BBA-Bioenergetics 1817(4):598-609

\section{Publisher's Note}

Springer Nature remains neutral with regard to jurisdictional claims in published maps and institutional affiliations.

\section{Submit your manuscript to a SpringerOpen ${ }^{\circ}$ journal and benefit from:}

- Convenient online submission

- Rigorous peer review

- Open access: articles freely available online

- High visibility within the field

- Retaining the copyright to your article

Submit your next manuscript at $\boldsymbol{\nabla}$ springeropen.com 